\title{
Linguistic Justice and the territorial imperative $\mathrm{e}^{\mathrm{i}}$
}

\author{
Philippe Van Parijs * \\ Chaire Hoover d'éthique économique et sociale, Université catholique de Louvain, Belgium and \\ Department of Philosophy, Harvard University.
}

In Critical Review of International Social and Political Philosophy 13(1), March 2010, 181-202.

\section{Justice, dignity, territory}

Throughout the world, the ever growing and irreversible dominance of English is frequently perceived and sometimes indignantly denounced as being grossly unfair. It definitely raises issues of cooperative injustice, i.e., relating to the unfair spreading of the burden of producing the lingua franca between those who have to learn it as a foreign language and those who have it as their mother tongue. It also raises issues of distributive injustice, i.e. relating to the inequality of opportunities deriving from unequally valuable native competences. But these issues need not worry us unduly, as the development that produces them is accompanied by a self-corrective process, or at least by an easy opportunity for sufficiently astute non-Anglophone communities to trigger such a process. The free-riding of Anglophones on the language learning of nonAnglophones - cooperative injustice — can be significantly offset by the free-riding of nonAnglophones on unprotected or poorly protectable information generated more than proportionally by Anglophones. And the language-based material and political advantage of native Anglophones — distributive injustice - will gradually get eroded and eventually be reversed by the cheapening of the learning of English as a result of intelligent policies such as an

\footnotetext{
*Email: philippe.vanparijs@uclouvain.be
} 
inexpensive ban on dubbing and of the very spread of the use of English in an increasing number of contexts. ${ }^{\text {ii }}$

For many of those most incensed by the growing dominance of English, however, the measures that would effectively tackle linguistic injustice as cooperative and distributive injustice make it worse in a third and more fundamental sense: as unequal dignity. Plundering the web may provide a clever form of compensatory free riding and a ban on dubbing an effective way of democratizing valuable language skills, but both will undeniably contribute to further accelerating the dominance of one language over all others. The primary, most fundamental injustice, it is often felt and claimed, resides precisely in what this dominance expresses: a lack of respect towards the 'dominated' languages and their native speakers, the ascription of an inferior, humiliating, insulting status to the people whose identities are closely tied to them. ${ }^{\text {iii }}$ Even if the burden of learning the lingua franca as a second language is shared fairly by the people who have the lingua franca as their mother tongue, even if second-language competence is widely and thoroughly spread or the residual handicap adequately compensated, there remains the painful fact that the language of one subset is being given a privileged standing far above all others.

For the resentment thus expressed to make ethical sense, justice must not only be a matter of distribution of outcomes or of opportunities, whether material or not. It may be the case that being regarded as belonging to an inferior category, whether caste, class or ethnic group leads to discrimination or to a lack of self-confidence that reduces one's welfare or life chances. But the idea is here that, irrespective of such effects, justice requires people to be granted equal dignity. ${ }^{\text {iv }}$ In this light, linguistic injustice as unequal dignity can plausibly be claimed to constitute the most fundamental form of linguistic injustice, and may well turn out to be the one hardest to fix. To address it, recurrent demystification and the symbolic assertion of the equality of all languages 
can do some good, but as pragmatic considerations keep restricting the scope for the latter, the former will sound more and more like a spiteful and ineffective outburst against the ever more pervasive dominance of English. ${ }^{v}$

There is, however, a third, arguably far more credible way of expressing and thereby pursuing the equal dignity of the various languages concerned and the associated identities. It consists in allowing each of them to be 'queen' in some territory, large or small, thereby granting a privilege, within the limits of that territory, to the identity associated with the language to which that territory has been ascribed. Within those limits, it is that language, and not a lingua franca, that is given the top function, that operates as the official language of the population as a political community. This guarantees that it is not always the same who need to do the bowing. It allows each linguistic community in turn, depending on location, to be the special one. It inhibits arrogance by blocking universal supremacy. Of course, the territories grabbed by the various languages will be far from equal. Some will be bigger than others, prettier, richer, more glamorous, more populated. But whether lavish or modest, there will be a place for every recognized language to be on top, and for the associated identities to be correspondingly honoured. The symmetry entailed in such a set up is the only really significant way in which linguistic justice as equal dignity can be implemented, consistently with the full acceptance of the systematic asymmetric bilingualism inherent in the adoption of a lingua franca.

\section{Linguistic territoriality regimes}

For this strategy to work, it must be realistic to expect those who settle on a particular territory to have the courage and the humility to learn the territory's official language if they do not know it already. Under present conditions — of comparatively high mobility and lingua franca spread — 
, this requires the implementation of fairly strong versions of what I shall call a linguistic territoriality regime, i.e. a set of legal rules that constrain the choice of the languages used for purposes of education and communication. The total absence of a linguistic territoriality regime would correspond to a regime in which the choice of language in any context is simply demanddriven: a language will be allowed for a particular purpose if a sufficient number of people want it to be used, with all linguistic aspects of social life adjusting swiftly to people's preferences under the sole constraint of threshold levels imposed by a cost-conscious use of resources. Whether a linguistic territoriality regime is in place is therefore a matter of degree: it depends on how firmly legal rules constrain this 'spontaneous' choice of language within the confines of a particular territory.

In the sense in which I shall be using the expression, therefore, a linguistic territoriality regime is not simply a language regime that is determined by the authority that rules over a particular territory. Which language(s) one is allowed to learn at public expense, to speak and write while expecting to be understood by public officials, or to get public information or services in, is always specified, explicitly or not, by the legislation of the territorially circumscribed political entity in which one might wish to exercise these various rights. In this broad sense, all language regimes, like all legislation, instantiate a territoriality principle, just as they instantiate a personality principle in the general sense that the rights they create are ascribed to individual persons. As I shall use it here, the notion of a linguistic territoriality regime does not refer to how much power linguistically distinctive communities are given over linguistically relevant legislation, but to how constraining or, on the contrary, accommodating public practices are to the linguistic wishes of the people who happen to live within given borders, irrespective of whether the relevant legislative authority corresponds to these borders. The more linguistic 
practices are restricted for reasons irreducible to a lack of sufficient demand, the stronger the linguistic territoriality regime involved and the smaller the room left for what is sometimes called a linguistic personality principle in the specific sense of each user being entitled to freely use the language of communication in any context. ${ }^{\mathrm{vi}}$

Whether out of a concern for freedom, for privacy or for effective implementation, existing linguistic territoriality regimes tend to confine themselves to the coercive regulation of (stateorganized, or state-subsidized, or most broadly state-recognized) education and to communication in public settings. The latter typically covers the internal working language of public administration and the language in which public officials communicate with the public, the language in which the courts operate and in which the public media broadcast, the language in which official information is displayed in public spaces, sometimes also the language of commercial messages in public spaces and of formal business in large private firms, and the language in which laws are published, elections organized and proceedings conducted in local, regional or national assemblies. ${ }^{\text {vii }}$

In all these cases, the coercive rules that define the linguistic territoriality regime interfere with the spontaneous interaction of probability-sensitive learning and maximin communication, which would otherwise govern the dynamics of linguistic repertoires. Probability-sensitive learning refers to the fact that the main determinant of the speed and quality of the learning of a language is the probability with which one can expect to have to practise that language, and this both for motivational reasons (the cost of the investment must exceed the expected benefit) and for opportunity reasons (our language teachers are our speech partners and TV channels). Maximin communication refers to the fact that the language picked for communication between plurilinguals systematically tends to be not the language best known by the majority, or best 
known on average, but the language best known by the speech partner who knows it least well. ${ }^{\text {vii }}$ A territoriality regime typically imposes public education in the local language even when probability-sensitive parents would prefer to have their children taught in another language. Or it imposes administrative or judiciary procedures in the local language even in situations in which it is not the maximin language and in which, therefore, another language would better facilitate mutual understanding. As a result, more people will learn the local language, or will learn it more thoroughly, that if probability-sensitive learning had been left unconstrained, thereby increasing the frequency with which the local language will be the maximin language. At the same time, more interactions will occur in the local language than if maximin were given free rein, thereby creating both a stronger incentive and a wider opportunity to learn the local language.

Consequently, the fact that the language of private communication should be immunized from the coercive grip of the linguistic territoriality regime does not mean that it is immune to its influence: which language is picked as the medium of schooling and public communication can obviously be expected to have a profound impact on linguistic competence and hence on the spontaneous (maximin-guided) choice of language even in totally uncoerced private communication.

In the standard case of a linguistic territoriality regime, one single language is imposed throughout the country concerned in the various contexts deemed in need of regulation. But in several cases, different languages are imposed in different parts of the same country. And in some cases, more than one language is imposed in part or the whole of a country (think, for example, of Catalonia and Luxemburg, respectively). Often applied unwittingly by nation states, the linguistic territoriality regime becomes salient when introduced, modified or strengthened as part of the formation of a new sovereign state (from Norway to Bangladesh and from Latvia to East Timor), 
but it has also been present from the start in the highly decentralised plurilingual Swiss Confederation and has been introduced, under strong pressure from the dominated linguistic communities, in a number of other plurilingual states such as Belgium in 1932 (with a number of explosive exceptions) and Canada in 1975 (with Quebec's notorious 'Law 101'). As democracy spreads or deepens throughout the world, especially in that majority of its states whose populations are more than marginally plurilingual, the linguistic territoriality regime will and - I shall be arguing - must play an ever more important role.

If the local language is a powerful language, which most immigrants spontaneously have a strong incentive to learn, the territoriality principle will hardly be felt, as only a very light constraint may be enough for the spontaneous interaction of differential learning and maximin communication to take over and keep that language firmly in place. But when this is not the case, when the spontaneous incentive to learn is weak, the enforcement of the territoriality principle will require perceptibly coercive measures, more or less visible, more or less effective, and more or less resented by parts of the population, non-natives and natives alike.

\section{Laponce's law and the survival argument}

Intelligently designed, a linguistic territoriality regime is both necessary and sufficient to keep competence in a local language sufficiently high and universal for that language to fulfil, legitimately and sustainably, the top function as the official language of the political community. And this in turn is necessary and, if anything is, sufficient, to secure equality of dignity between peoples whose identities are closely associated to a language. This is my central argument in favour of linguistic territoriality. I shall consider objections to it below, but want to consider first 
some related but distinct arguments which may add further strength to it under specific circumstances.

Firstly, the justice-as-equal-dignity case for a linguistic territoriality regime gains further strength once linguistic communities understand, and believe that the others understand, that in a high-mobility, high-communication context, a linguistic territoriality regime provides the only way of preventing the gradual erosion of their language that is not unacceptably coercive. This strengthening of the argument does not rely on anything like a holistic right of each language to survive, or to have a fair chance to survive. Nor does it appeal to the need to preserve the societal culture associated with a particular community's inherited language as a necessary component of the resources required for leading a meaningful life. It simply says that the argument for a linguistic territoriality regime on grounds of equal dignity becomes stronger once it is understood to be the only effective and acceptable way of preventing the gradual extinction of the language with which a community's identity is linked. To understand this, it is important to realize that there are two fundamentally distinct mechanisms that threaten the survival of languages.

One of them is top-down. It consists in a national political authority deliberately imposing the national language at the expense of local idioms, mainly through compulsory schooling and compulsory military service. As the trans-national migration of individuals and families expanded, the same tool of compulsory education in the national language, routinely coupled with a stigmatisation of the immigrants' original languages, was massively used to secure the assimilation of immigrants and their offspring. Thus, the same basic process applied in one case to the linguistic assimilation of dialect users and national minorities stuck within the borders of a state with an official language different from their mother tongues, and in the other to the assimilation of ethnic minorities stemming from immigration. In both cases, it can be aptly 
described, using Gellner's (1993: 139-140) telling metaphor, as one that gradually converts the linguistic map — and tirelessly re-reconverts it, as new stains appear — from a Kokoshka landscape into a Modigliani portrait, from a motley patchwork of coloured spots to a neat juxtaposition of smooth surfaces demarcated by firm lines.

However, this Gellner-type, top-down, state-driven mechanism does not constitute the only mechanism through which weaker mother tongues get displaced by stronger ones in a postagrarian, frequent-contact, high-mobility context. There is another, bottom-up, people-driven type of mechanism, a soft brand of Modiglianisation as it were, which can be captured in what I shall call Laponce's law: the kinder the people, the unkinder the languages. ${ }^{\text {ix }}$ Languages can coexist for centuries when there is little contact or not at all between the parts of the population that speak it. But as soon as people start talking, trading, working with each other, courting each other, having children together, the weaker of the two languages will be slowly but inexorably driven out by the other, by the one which people have a stronger incentive to learn because of its being more prestigious or more widely spread. ${ }^{\mathrm{x}}$ This macro-law is nothing but one macroscopic reflection of the interaction of the two micro-mechanisms referred to earlier: probability-sensitive learning and maximin language use.

Quite often, the top-down and bottom-up mechanisms operate side by side and reinforce each other. But sometimes the Laponce-type mechanism is observable in a fairly pure form, for example in Quebec until 1975, in Flanders between 1898 and 1932, or in Brussels up to the present. In these areas and periods, officially affirmed bilingualism is supposed to have switched off the Gellner-type mechanism as regards the two recognised languages, while the dominant language (English in Canada, French in Belgium) keeps spreading at the expense of the weaker one through differential conversion rates of both native and immigrant families. ${ }^{\mathrm{xi}}$ Because 
language is a means of communication, there is an intrinsic vulnerability of the weaker language, which does not plague in the same way other components of culture, such as religious practices or cooking habits. How quickly the stronger language will invade contexts previously occupied by the other will vary greatly as a function of such factors as the scope of immigration, the progress of urbanization, the degree of residential and educational segregation, etc. But once the linguistic communities involved become aware that laissez-faire leads to the gradual erosion of one of the languages, it is hard for those who identify with it not to feel despised, treated unjustly, denied equal dignity, if they are not allowed to use effective means to prevent this predictable agony.

\section{Survival without territory?}

According to perceptive observers of this process, such as Jean Laponce, these effective means, can only be provided by a linguistic territoriality regime. ${ }^{\text {ii }}$ But is there really no alternative? After all, if people do not want their language to die, it is simply up to them to use it. However, two features of the mechanism that leads to the erosion of a weaker language combine to prevent this voluntaristic alternative from holding much promise.

To start with, there is the standard collective action problem as it applies to the choice of language for both education and communication purposes. Consider education first. Parents may realize that if all send their children to dominant language schools, their own language will gradually be eroded and disappear, and want to prevent that. But if other native parents do not opt for the dominant language school, the language will not be eroded, and it is then in the interest of each family, taken separately, to send its own children to such a school. If others do defect in this way, on the other hand, no particular family will make a difference and each may therefore just as 
well send its children to such a dominant language school. As regards next communication, consider the case of shopkeepers in an area with many customers who speak a dominant language different from the local one. Again, whether their competitors comply or not with the voluntary policy of deviation from the maximin in order to save their language, it will be in any particular shopkeeper's self-interest to try to gain or retain customers by defecting, i.e. by accepting to use the dominant language. To prevent individual rationality from defeating the attainment of an option preferred even by all members of a particular linguistic community, tireless collective mobilization would therefore be required. Whether in matters of education or communication, well-targeted legislation is so much less onerous that the strenuous informal monitoring and painful mutual sanctioning without which the voluntaristic strategy cannot durably succeed.

Secondly and even more crucially, one must remember that, in the terms I used to formulate Laponce's law, it is the kindness of the people that provides the stronger language with its unkind claws. Speakers of the weaker language can, in order to block the process leading to its disappearance, insist on speaking their own language and on pretending they understand nothing else in the many informal contexts in which the dominant language is the maximin language, and is therefore the one that makes communication most fluid and mutual understanding least problematic. Implementing the will to maintain one's language through this stubborn, exclusionary and hence 'unkind' insistence on using one's language unavoidably generates a permanent climate of face-to-face tension between members of the two linguistic communities. Coercively imposed rules, even imperfectly enforced, have the advantage of reducing — without suppressing — these strains: it is less 'aggressive', 'nasty', 'sectarian', 'unwelcoming', 'pettyminded' to say 'Sorry, I know it is stupid, but the law does not allow us to provide schooling, information or other services in your language' than to say 'Sorry, I refuse to listen or speak to 
you in your language, or to provide services in the language in which you would find it easiest to receive them, even though nothing but my bad will prevents me from doing so'.

Once it is admitted, for these two reasons, that voluntarism does not provide a serious alternative, and hence that some set of coercive rules regulating the teaching and public use of languages is required, it still does not follow that these coercive rules should take the form of a linguistic territoriality regime. The linguistic constraint needed to protect the weaker language could in principle either apply to all people in a specific place — the linguistic territoriality regime - or to specific people wherever they are. The latter option could be called a linguistic personality principle, interpreted this time in a coercive sense, not in the permissive sense mentioned above (section 2): people with a specific mother tongue would be obliged to learn or use it in specified contexts, wherever they happen to be inside the area in which the legislation applies. This second option is not exactly as commonly used as the first one. The compulsory use of Hebrew, Latin or Arabic for liturgical purposes could be interpreted as approximations of it, and so can the restriction to parents who did not graduate from Quebec's English-language school system of the obligation to send one's children to a French-language school, or a rule briefly implemented in Brussels in the 1970s that forced people educated in Dutch to send their children to a Dutch-medium school.

Which of the two formulas offers a stronger guarantee of survival to a threatened language depends on the respective probabilities of the homeland running empty on the one hand and of the race losing interest in procreation (or intermarrying heavily) on the other. The former formula, however, has several decisive advantages over the second one, which jointly account for its far broader adoption. Firstly, it is arguably less coercive: one can change one's residence, not one's native tongue. Secondly, it is far easier to implement because of the place-bound nature of 
many of the services concerned (educational, administrative, judiciary, etc.). The third reason is more subtle, yet ultimately the most important. To understand it, let us remember the fundamental objective assigned here to the implementation of a linguistic regime. The aim is not, as such, to guarantee the survival of a vulnerable language, but to secure the equal dignity of the identity associated with it. And for this objective to be achieved, it is not enough that survival of the language should be secured. The latter must also be enabled to function in top position, i.e. as the public language of its native speakers' political community. At first sight, this could be achieved through a devolution of powers to non-territorial as well as to territorial linguistic communities. But this is not the case, for reasons that are worth spelling out.

The non-territorial linguistic federalism thus suggested was proposed by Karl Renner (1918), the Austrian social-democratic thinker and statesman who first set out to think systematically about how democracy could function in a multilingual context. In his elaborate proposal, each of the eight nations comprised in the Austro-Hungarian Empire (Germans, Czechs, Poles, Hungarians, Slovenes, Slovaks, Croats, Italians) were to be given their own Parliament and granted full autonomy in matters of culture, education and some aspects of social policy, with issues of joint concern settled through negotiation between the representatives of the various nations. The Austro-Hungarian Empire fell apart shortly after the book was published, and Renner's scheme was therefore never tried in the context for which it was meant. But some form of non-territorial federalism was tried elsewhere, for example in Estonia in 1925, in Cyprus in 1960 or in South Africa in 1984, never with great success.

This is hardly surprising, as it has two intrinsic defects which territorial federalism avoids. One is that it is akin to racial apartheid in giving people living in the same places access to services that may be of greatly different quality, at least if the linguistic divide correlates with 
economic inequality, simply by virtue of a feature — one's mother tongue — which is hardly less a matter of arbitrary luck than one's race. Unequal rights in different places does not have the same humiliating, degrading nature. The other defect derives from the irreducibly spatial nature of any coherent, comprehensive project for a political community. There is a deep structural strain inherent in any set up in which distinct political communities elaborate and discuss their own projects separately and then need to negotiate and compromise with each other on countless issues, because they happen to share the same territory. Non-territorial political communities, therefore, are not the way to go.

Consequently, if Laponce's law is to be counteracted, territorial legal constraints are to be strongly preferred to personal ones, not only because they are less coercive and more convenient to implement, but also because they are far better suited to enable each protected language to sustainably function as a political language, and hence to be granted the corresponding dignity.

\section{Laitin's sons of the soil and the pacification argument}

In addition to the preservation of some degree of symmetry and the prevention of linguistic erosion, both directly relevant to the pursuit of linguistic justice as equal dignity, the pacification of inter-ethnic relations is also frequently invoked to justify linguistic territoriality regimes. ${ }^{\text {xiii }}$ To spell out this argument, consider Fearon and Laitin's (2000) finding that most cases of civil violence in recent decades were the making of sons of the soil, i.e. of autochthonous populations that felt invaded by members of a distinct ethnic group moving in, either spontaneously or in organised fashion, from another part of the same multi-ethnic state, without trying to integrate into the local population, and in particular without bothering to learn the local language. Especially if they gradually get outnumbered — or fear getting outnumbered — by the 
immigrants, without any legal means of preventing it, they see violence as the only way of preserving their legitimate interests. In a more or less acute form and with a more or less pronounced time lag, many of the inter-ethnic conflicts most familiar to us — from Ulster and Palestine to East Timor and Kosovo - , illustrate the same basic pattern. In this light, a firm and unambiguous linguistic territoriality regime may be expected to have a pacifying impact, at least in those circumstances in which the unbalance of power is not such that sons of the soil spontaneously surrender to the 'invaders' and switch to the language of the 'colonizers', accepting their linguistic inferiority as one of the many facets of their subjection.

However, David Laitin (2004) also documented a significant positive correlation between the institutionalization of language rights - at least some of which can be assumed to consist in some linguistic territoriality regime - and the occurrence of inter-ethnic violence. This sounds like a refutation of the argument just sketched on behalf of linguistic territoriality regimes. But it is not. For Laitin's interpretation of this correlation is not that the institutionalization of language rights causes inter-ethnic violence, but rather that both are the consequence of the weakness of states. Hence, his analysis is consistent with the view that the concession of (the right sort of) linguistic rights is a way of taming inter-ethnic conflict, just as the strong correlation between the occurrence of flu and the absorption of flu medicine is consistent with a favourable healing impact of (the right sort of) flu medicine. Moreover, on the background of his own 'sons of the soil' thesis, it is worth distinguishing, among linguistic rights concessions, between 'territorial' and 'personal' ones, as only the former can be expected to contribute to pacification, whereas the latter should rather be expected to have the opposite effect.

That the linguistic territoriality regime may contribute to the pacification of inter-ethnic relations remains therefore plausible enough. And this fits in with its justification in terms of 
equal dignity. But the connection needs to be made cautiously. First of all, Laitin's data and analysis suggest that there is a surer way of stamping out ethnic conflict: strengthening the state without any linguistic concession. But even leaving aside that this is seldom a real option in the countries concerned, what is best for peace is not necessarily best for just peace. The case for a linguistic territoriality regime is that it provides a way of pursuing lasting peace in a way consistent with justice as equal dignity. This is particularly clear when the main impulse behind the violence of the 'sons of the soil' is their feeling of being humiliated by arrogant invaders who despise their language and culture.

However, it must be conceded that hostility towards newcomers speaking a different language may have other sources than a perceived threat to one's dignity. It may well stem chiefly from the fear of tougher competition for jobs, housing or public services, or from the fear of having one's community life impoverished. Thus, Jean Laponce (2004) stresses the negative externality that arises for a local community when natives of their language are replaced by nonnatives who cannot or will not learn it. This negative externality is particularly onerous for local people poorly equipped for communication with aliens culturally quite different from themselves. All sorts of mutual informal services on which one routinely relies - from keeping an eye on each other's property to organizing child care or taking elderly people to the hospital —, if not made impossible, are made significantly more difficult if communication and trust are impaired by the lack of a common language. An effective linguistic territoriality regime addresses such concerns, whether by having a dissuasive effect on the inflow, by accelerating the development of communication and trust between the old and the new, and by creating a realistic expectation that the newcomers will adjust to the locals rather than the other way around, thereby enabling the locals to retain at least a temporary advantage. 
In addressing these concerns of the local population, the linguistic territoriality regime may switch off a process that could generate desperation and violence — in the worst case antiimmigrant racial riots - on the part of those who feel most threatened. Mechanisms of this sort establish a link between linguistic territoriality regime and pacification. However, the source of the violence to be averted is not always, or not always mainly, injustice interpreted as unequal dignity or in any other way. Indeed, the motive may be the fear of losing a privileged position, relative to disadvantaged intruders. Yet, the linguistic territoriality regime can be defended even then as a way of fostering peace consistently with justice: justice as equal dignity because of the counterfactual symmetry pointed out earlier, and distributive justice too to the extent that it is part of the core of an effective linguistic territoriality regime that it should efficiently equip newcomers and their offspring with proficiency in the local official language. Pacification, however is only a lateral aspect of the fundamental justification. The linguistic territoriality regime recommends itself on grounds of justice as equal dignity even, indeed perhaps especially, in those cases in which the 'sons of the soil' are too subdued or too intimidated or too peaceloving to threaten the public order.

\section{Which languages, which borders?}

Before the implementation of the linguistic territoriality regime can get off the ground, however, it is indispensable to tackle the prior question of which languages should be granted a territory and of which territory this should be. There cannot be a neat answer to this dual question, but the guiding idea should be that there must be a sufficiently large and geographically concentrated number of people who regard themselves as sharing the same language and are willing to pay the cost, if any, of implementing a linguistic territoriality regime. 
It is important to clarify straight away the relationship between this guiding idea and something sometimes called the 'law of the soil', or the claim of an ethnic group to its ancestral land. It does not matter as such, when the linguistic territoriality regime is being put into place, for how long the linguistic community has been living on the territory concerned. It only matters indirectly as it is likely to be strongly correlated with the degree of geographical concentration of the population and may significantly affect the community's willingness to pay the cost of implementing the linguistic territoriality regime. Providing it is sufficiently large and concentrated, therefore, a population stemming from fairly recent immigration may qualify no less than one which has been living in the same place for millennia. It is in the very nature of the territoriality principle, however, that once it is in place a crucial distinction is being made between the 'locals' and the 'immigrants', who are expected to adjust linguistically to the local environment.

Fairness is respected to the extent that it can credibly be said: 'You need to learn our local language here just as we would need to learn yours if we settled in your own place'. Some people's place may be small or poor or very cold or very hot, and the probability of my ever settling there close to zero, but the symmetry needed for equal respect does not require equal attractiveness or equal probability. ${ }^{\text {xiv }}$ For those allophone immigrants who do not have a protected linguistic homeland — the Kurds, the Arameans, the Baluba - , the solution cannot consist in allowing them to grab a territory wherever they decide to migrate, but where their presence for centuries has made them sufficiently concentrated over a large area for an appeal to territorial protection to make sense. In many cases, no doubt, there will be disagreement about whether such a principle was tacitly in place and for how long: the English-Only movement in the US, for example, takes for granted that it was when the Hispanics arrived en masse, yet that it 
was not when the first Anglophones settled in Los Angeles or Nuevo México. This makes it all the more urgent to clarify the linguistic status of each place, using the above guiding idea to select the languages and draw the borders.

Unless these borders are just making explicit the linguistic territoriality regime inherent in much nation building, they are bound to be contentious. Many compromises will need to be made between geographical coherence and linguistic homogeneity, between drawing borders so that they include as many natives as possible of the language concerned and as few natives as possible of the other languages. Whichever compromises are made, some people will be stuck on the 'wrong' side of the border. But this need not be a disaster. The vested rights of such linguistic minorities can be protected through special measures that will be phased out as the generation to which they belong dies out. Moreover, languages other than the official one can thrive and even get official support. The lines of the Modigliani painting entailed by the regime must be firm and the contrasts can be sharp, but the colours need not be dark. What matters is that the protective measures be powerful enough to keep promoting the official language into maximin position often enough for all permanent residents to have both the desire and the opportunity to acquire an adequate competence in the local official language. Failing this, the local language could not legitimately be given the highest function.

\section{Net benefit or net cost?}

The key condition, however, is that there must be, with regard to a particular language and particular borders, a community willing to bear the cost of implementing the linguistic territoriality regime on behalf of its language. What does this cost consist in? Most obviously, foregoing some economies of scale in the production and dissemination of educational material, 
legislation or administrative documents. How much is thereby being foregone chiefly depends on the respective sizes of the linguistic communities whose languages are being adopted or abandoned, respectively, as a result of the territoriality regime being implemented. This is why the existence of a critical mass of native speakers is a decisive consideration.

However, the loss inherent in scale shrinking may be more than compensated by some positive efficiency effects of adopting the native language of a larger share of the population for educational and official purposes. Take the case of the Democratic Republic of the Congo, where an educational system (dys)functioning essentially in French produces generations of illiterates. Given the extreme dearth of resources now and in the foreseeable future, it is worth exploring the option of organizing primary and secondary education in the country's four recognized national languages (Kikongo, Swahili, Lingala and Ciluba) in the parts of the country in which they prevail, while making official use of those languages in public administration and political life, again in the corresponding areas. Of course, this would require the production of teaching material and administrative documents for a population averaging a quarter of the country's 50 million population, instead of producing it for the whole country or importing it from other 'francophone' countries. But the performance of a poorly equipped educational system could be expected to be enhanced if it were to function in languages in which, say, $90 \%$ of its pupils are competent, rather than in one in which $7 \%$ are. Moreover, the accountability of politicians and public officials, and hence the contribution of public decisions to the welfare of the population, can reasonably be expected to increase as a result of their having to function in a language understood by the majority of the citizens instead of just a tiny elite. ${ }^{\mathrm{xv}}$

In this light, it looks as if there may well be circumstances in which implementation of the linguistic territoriality regime generates a net benefit, rather than a net cost for the local 
population. This suspicion is further reinforced by the following consideration. With no linguistic territoriality regime in place (or, worse still, with a foreign language imposed), it is as if locals had to pay customs tariffs on their own soil, to use Benedict Anderson's (1993: 615) illuminating metaphor, by having to learn a foreign language and to communicate clumsily in it even in their own homeland. Once the principle is in place, it is for the non-locals to pay the 'customs tariffs' of language learning and uncomfortable communication. Obviously, the regions claiming this symmetry of 'customs tariffs' must feel sufficiently confident that the non-natives they could benefit from will bother to pay them, rather than just turn elsewhere.

It is one aspect of the general point metaphorically expressed in this last observation that constitutes arguably the main component of the cost intrinsic to any implementation of the linguistic territoriality regime under contemporary conditions. It consists in the growing asymmetric flow of human capital towards what I shall call the ground floor of the world, i.e. those parts of the world in which English, the worldwide lingua franca, is the official language, essentially the greater part of North America, the British Isles and Oceania. ${ }^{\mathrm{xi}}$

It is only recently that it has become possible to document with any statistical precision the existence of such an asymmetric flow. Thus, Docquier and Marfouk (2005: 23) observe that 'immigrants are particularly educated in Canada, Australia, New Zealand, the United States and the United Kingdom', i.e. in the world's five main Anglophone countries. Their estimates indicate that three of these countries (the US, Canada and Australia), totalling hardly more than $5 \%$ of the world population, house nearly $75 \%$ of the world's 'expatriate brains', defined as those graduates of higher education who are not currently domiciled in their country of birth. In 2000, the non-anglophone OECD countries had an aggregate net deficit of 2.1 million brains (down from 2.8 million in 1990), i.e. there were over 2 million more graduates born in those countries 
who were living elsewhere than there were graduates born elsewhere living in those countries. By contrast, the six anglophone OECD countries enjoyed a massive surplus of 13.9 million brains (up from 9.2 in 1990), 9.9 million of them in the USA alone (up from 5.9 million in 1990). Put paradoxically: out of the 12 million brains sucked into the rich portion of the planet, 14 inhabit its Anglo compartment.

To understand what underlies this strong asymmetry, just imagine you are thinking of moving abroad. Which country you will seriously consider moving to will no doubt be affected by many factors, and above all by job opportunities. However, (1) which job opportunities you are likely to be best informed about will be significantly affected by whether or not you know the country's language; (2) which job opportunities you feel you would be (or could quickly become) suitable for will be affected by how well you master the country's language; (3) if you have a family, which country you would find it sensible to move to is bound to be influenced by which languages your spouse and children understand and speak, or could easily learn, or which it makes independent sense for them to learn ${ }^{\mathrm{xvii}}$; and (4) how genuinely welcoming a country's local population is likely to be towards foreigners will also depend on how quickly and how well they can reasonably expect the newcomers to master their language, thereby avoiding the disruptive negative externalities mentioned above.

All of these considerations have some weight for migrations of all sorts, but there are four reasons why they can be expected to be particularly weighty for the migration of the high-skilled. (1) The high-skilled are more likely to have bearable job opportunities at home and can therefore afford the luxury (relative to the needs of sheer survival) of not inflicting too much of a linguistic adjustment cost on themselves and their families. (2) The jobs for which they would qualify generally have far greater linguistic requirements than unskilled jobs. (3) For the time being, the 
probability that high-skilled workers and their families already have, before migration, a good knowledge of at least one foreign language is far higher than for other workers. (4) Unlike the less skilled, the high-skilled have a sizeable probability of having gone abroad to study, and where they have studied is bound to affect where they may later consider moving to, while being greatly affected not only by what languages they know, but even more by what language they find important to try to know better. Indeed, asymmetry in the net flow of students is at least as pronounced as in the net flow of graduates.

For all these reasons, as one language gets ever better known abroad, and therefore also ever more useful to know better, the propensity for workers in general, but especially for highskilled workers, to migrate towards countries in which that language prevails, can only be growing — other things remaining equal. In a world in which a number of mother tongues have developed into regional lingua francas, the asymmetry just described can be expected to generate a number of regional attractor basins into which the high-skilled will tend to descend from the linguistic hills formed by countries whose languages are hardly known abroad. But in a world in which English is being snowballed into the one universal lingua franca, we can expect the formation of a huge ground floor visible from all the linguistic hills and mountains of the world, from all the upper floors in which more obscure, less penetrable mother tongues are being spoken, but in which the lingua franca is getting ever better known; a huge ground floor towards which the high-skilled of Finland and Hungary but also of Germany and France, will tend to wander more and more, without anything like a matching tendency for the high-skilled of the United States or Britain to climb up to the French plateau, let alone to the Hungarian peak. 


\section{Territoriality made cheaper}

In an increasingly knowledge-based economy, it is not difficult to understand how heavy a cost this systematic net loss of highly selected, expensively trained people may mean in terms of economic dynamism. With further spreading of the lingua franca, one can expect a constant swelling of the pool of potential recruits for high-skilled jobs on the ground floor. With such a large pool, the countries concerned can allow themselves to be selective. ${ }^{\text {xiii }}$ The more economic dynamism is boosted as a result, the more attractive these places become, language aside, and hence the greater the scope for more creaming off of the high skills of the rest of the world.

For upper-floor populations, this chronic net outflow of human capital constitutes a significant cost likely to weigh far more than any economies of scale foregone. However, the outflow is necessarily accompanied by three epiphenomena which may amount together to a huge discount in terms of long-term cost. First, there are the remittances sent back home by migrant workers to their close or more remote relatives. For various reasons, including the enhanced safety of trans-national bank transfers and the dwindling cost of keeping in touch, the volume of these remittances has been growing steadily, to the point of outstripping the volume of development aid. ${ }^{\mathrm{xix}}$ Secondly and probably more significantly as regards the highly skilled, there is the transfer of knowledge by those returning to their country of origin, whether by virtue of what they learned when studying, training and working in a foreign country, or by virtue of the network of trusted contacts they established during their stay abroad. ${ }^{\mathrm{xx}}$ Thirdly, the presence on the ground floor of bright brains from all over the world makes the ground floor particularly vulnerable to the cheap worldwide spreading of whatever knowledge it possesses and produces. The spread of English as a lingua franca induces asymmetric free-riding on Anglophone intellectual production. ${ }^{\mathrm{xxi}}$ The presence of highly trained non-Anglophones on Anglophone soil 
greatly helps in making this information immediately identifiable, understandable and usable in the rest of the world, while the reverse is not true.

There is no doubt that these three mechanisms soften the blow, but not to the extent of preventing the gap from deepening, between the ground floor and its ever wider and deeper attraction basin, in terms of knowledge and wealth creation. Hence, the net cost for the upper floors, in terms of steady relative or even absolute decline, is something they should worry about, perhaps even so much that they may wonder whether it makes sense to keep inflicting it upon themselves. After all, it is up to them to give up their linguistic territoriality regime. They could make settling in a non-Anglophone country linguistically as comfortable for the highly skilled of the world as settling on the ground floor, whether in terms of administrative procedures, schools or courts, and even in terms of political life. By doing so, they would go a long way towards cancelling the linguistic competitive advantage of the ground floor. In the process, however, they would also trigger a powerful mechanism which may look innocuous enough at first but will soon displace local languages in an increasing number of contexts. As argued above, this would amount to a surrender of linguistic justice as equal dignity — not simply to a gradual flattening of the linguistic surface of the globe.

Nonetheless, a carefully and firmly limited use of this strategy may make sense, and even prove essential to keep the cost bearable. It consists in lowering to ground floor level, not the whole of a non-Anglophone country, but duly circumscribed 'linguistically free zones', i.e. small areas in which the constraints of the linguistic territoriality regime are waived. The highly skilled and their families who settle in these zones, typically selected because of their high-tech vocation, would be relieved of the heavy 'tax' of having to learn the local language. As a consequence, the lingua franca would gradually rule within these enclaves about as imperially as 
it does on the real ground floor. The organization of a significant proportion of higher education and scientific research in the English medium constitutes a minimal component of the 'linguistically free zones' ${ }^{x i i}$ In the absence of such an exception to the linguistic territoriality regime, the spreading of competence in the lingua franca (and of the desire to improve it) would keep swelling the pool of students wanting to study in the higher education institutions of the ground floor, thereby enhancing the latter's ability to select the best and further improve the quality of its higher education at the expense of what can be achieved elsewhere - bearing in mind that 'quality' of one's peers is arguably the chief determinant of anyone's educational achievement.

Instead of lowering parts of the upper floors, one can try, secondly, to exploit the advantages of being on that floor. One potential advantage is that having a less widely spread language, by maintaining a distinctive culture, may make it easier to nurture a feeling of community and thereby to instil a sense of loyalty that will inhibit the opportunistic search for the highest net return among highly-skilled workers henceforth made more mobile by their competence in English. Another potential advantage is that being a speaker of a less widespread language and having to learn at least one other language as a result enables those who have to make that effort to escape the arrogance and the insensitivity to cultural differences that come too easily to those who have never had to undergo that humbling process and are invariably in the comfortable position of being able to use their mother tongue. Without noticing, such arrogance and insensitivity trigger rancour, resentment, even hatred. This may prompt actions against whose risk one needs to protect oneself, sometimes at great expense. Being (perceived as) less arrogant is an asset which the upper floors of the world can intelligently exploit — and already do. 
With the inbuilt discounts listed above and a judicious use of the strategies just sketched, a number of linguistic communities throughout the world will feel that it is worth shouldering the expected cost of sticking to a sufficiently effective version of the linguistic territoriality regime, the cost of saving their soul, of preserving their identity, of upholding their dignity. Of course, within the existing institutional world order, the more the lingua franca spreads, the more vulnerable the countries concerned become. But at the same time, the more the lingua franca spreads, the less unrealistic the prospect of creating the linguistic preconditions for a European and worldwide institutional order that will make such a choice less costly.

\section{Notes on contributors}

Philippe Van Parijs holds the Chaire Hoover d'éthique économique et sociale at the Université catholique de Louvain and is a regular Visiting Professor of Philosophy at Harvard University. His recent publications include L'Allocation universelle (2005, with Yannick Vanderborght) and Redesigning Distribution (2006, with Bruce Ackerman and Anne Alstott).

\section{References}

Ammon, U., 2001. The dominance of English as a language of science: effects on other languages and language communities. Berlin: Gruyter.

Anderson, B. R.O., 1993. Nationalism. In : J. Krieger, ed., The Oxford companion to the politics of the world. Oxford: Oxford University Press, 614-619.

Docquier, F. and Marfouk, A., 2005. International migration by educational attainment (1990-2000), Release 1.1. Washington DC: World Bank Publications, 1-8.

Fearon, J. D. and Laitin, D. D, 2000. Sons of the soil: immigrants and the State. Stanford University: Dep. of Political Science. 
Gellner, E., 1983. Nations and nationalism. Oxford: Blackwell.

Kapur, D. and McHale, J., 2003. Migration's new payoff. Foreign Policy, 139, 49-57.

Kodelja, Z. and Krivic, M., 2007. Language rights in education in Slovenia. In: Education, law and language rights. Antwerp: European Association for Education, Law and Policy. 1-17.

Laitin, D. D., 2004. Language policy and civil war. In: P. Van Parijs, ed., Cultural diversity versus economic solidarity. Brussels: De Boeck Université, 171-88, at www.etes.ucl.ac.be/Francqui/Livre/Livre.htm.

Laponce, J., 1984. Langue et territoire. Québec: Presses uniersitaires de Laval. Translation: Languages and their territories. Toronto: University of Toronto Press, 1987.

Laponce, J., 1993. The case for ethnic federalism in multilingual societies: Canada's regional imperative. Regional Politics and Policy, 1, 23-43.

Laponce, J., 2004. Comments on Laitin and Grin. In : in P. Van Parijs, ed., Cultural diversity versus economic solidarity. Brussels: De Boeck Université, 203-10, at www.etes.ucl.ac.be/Francqui/Livre/Livre.htm

Laponce, J., 2006. Loi de Babel, et autres régularités des rapports entre langue et politique. Québec: Presses de l’Université Laval.

Levine, M. V., 1990. The reconquest of Montreal: language policy and social change in a bilingual city. Philadelphia: Temple University Press.

Maiworm, F. and Wächter, B., 2002. English-language-taught degree programmes in European Higher Education. Trends and Success Factors. Bonn: Lemmens.

Mukash, K., 2003. Situation linguistique et dynamique des langues en République Démocratique du Congo contemporaine. Kinshasa: Observatoire des langues nationals, 13.

Nelde, P. and Darquennes, J., 2001. Sprachwechsel in der Großstadt - eine Brüsseler Perspektive. In: J. Born, ed., Mehrsprachigkeit in der Romania. Wien: Praesens, 91-104.

Papaux, A., 1997. Droit des langues en Suisse: Etat des lieux. Revue suisse de science politique, 3, 131-134.

Patten, A., 2003. What Kind of Bilingualism?. In: W. Kymlicka and A. Patten, eds., Language rights and political theory. Oxford: Oxford University Press, 296-321. 
Réaume, D. G., 2003. Beyond personality : the territorial and personal principles of language policy reconsidered. In: W. Kymlicka and A. Patten, eds., Language rights and political theory. Oxford: Oxford University Press, 271-95.

Renner, K., 1918. Das Selbstbestimmungsrecht der Nationen. In: besonderer Anwendung auf Oesterreich (Leipzig and Wien: Franz Deuticke).

Schlesinger, A. M., 1998. The disuniting of America: reflections on a multicultural society. Revised and enlarged edition. New York: W.W. Norton.

Stevens, G, Jin, K. and Song Hyun Jong, 2006. Short-term migration and the acquisition of a world language. International Migration, 44, 167-79.

Van Parijs, P., 2000. The ground floor of the world: on the socio-economic consequences of linguistic globalisation. International Political Science Review, 21, 217-33.

Van Parijs, P., 2004. Europe's linguistic challenge. Archives européennes de sociologie, 45, 111-152.

Van Parijs, P., 2008. Grab a territory! Linguistic dignity and English dominance in the European Union. In: J. Poirier et al. eds., Ties that bind: accommodating diversity in Canada and the European Union (Bern-BerlinBrussels: Peter Lang).

\section{Notes}

\footnotetext{
${ }^{\mathrm{i}}$ This chapter is a component of the draft of a book in progress under the title Linguistic Justice for Europe and for the World (Oxford University Press). Some of the claims it takes for granted are being presented and defended in other components of this book, which will be referred to below as $L J$ followed by chapter or section number. A first rough formulation of the book's main claims can be found in Van Parijs (2004). A couple of sections of this chapter also appear in Van Parijs (2008).

${ }^{\text {ii }}$ See $L J 2$ and $L J 3$ on cooperative justice and distributive injustice, respectively, and on how best to address them.

iii It need not be assumed that people's collective identity is universally linked with a language, or that it is more often, or more strongly, linked with language than with religion or ethnic origin. What is special about languages is that a privilege needs to be given to one of them across borders in today's world (see $L J 1$ ), whereas there is no
} 
analogous case for a privilege to one religion or one race. (There is an analogous case for the privilege a city must be given as the political capital of a supra-national political entity, but this is a privilege granted to a space where all citizens of this entity must be welcome, not to a particular group of people.

${ }^{\text {iv }}$ It can be linked, for example, to the importance attached by Rawls to society's institutions being arranged so as to provide the 'social bases of self-respect', no matter what effect these may have on the distribution of the social and economic advantages covered by the difference principle. Other theories of distributive justice may accommodate this idea differently. For example, prior to discussing which metric of distribution would be most relevant, they may require that all members of society must be given an equal status, that they cannot have their identity disparaged, ranked lower than that of others.

${ }^{\mathrm{v}}$ See Van Parijs (2008) and $L J 4.1$ for a discussion of these first two strategies against linguistic injustice as unequal dignity and their limitations.

${ }^{\text {vi }}$ On this distinction (often misleadingly used), see Réaume (2003) and Patten (2003). I discuss below (section 4) a coercive interpretation of the personality principle.

${ }^{\text {vii }}$ Here is, for example, the Slovenian version of the linguistic territoriality regime, as laid down in Slovenia's 2004 Law on the Public Use of the Slovenian Language: 'The law states that Slovenian shall be used orally and in writing in public life... It stipulates that the names of all state bodies, local administrations, public organizations, public companies, and political parties shall be in Slovenian. Public insignia as well as the names of private companies, premises and shops should be in the Slovenian language, too. All proceedings involving public and private companies should be carried out in the Slovenian language. Slovenian is also prescribed as the language of public notices, conferences, press releases, announcements, and product labelling and instructions. Contracts with Slovenian companies must be written only in Slovenian and only this version may be considered as an original. In addition, all companies and individuals under private law must communicate with their customers in Slovenian and only people with appropriate knowledge of Slovenian can be employed in jobs that require communication skills'. (Kodelja and Krivic 2007, p. 9.)

viii The description of these two mechanisms and their explosive interaction is refined and qualified in $L J 1$.

ix The phrasing is mine, but the process at work is perceptively described by Jean Laponce $(1984,1993,2006)$.

${ }^{\mathrm{x}}$ See, for example, the statistics on the language prevailing in mixed (French/English) couples in Canada (Laponce 1993, pp. 34-35). 
${ }^{x i}$ The realization of the steady progress of English in Montreal (despite the inflow and higher birth rate of catholic francophones) and of the steady progress of French in Brussels and all major Flemish cities gave the key impulse to the demands for a linguistic territoriality regime as a more serious way of implementing the equal dignity of the two languages than the sheer formal assertion of equality and nationwide bilingualism. See Levine (1990) on Montreal and Nelde and Darquennes (2001, pp. 94-6) on Brussels.

${ }^{x i i}$ Along the same lines in the Swiss context, see e.g. Papaux (1997 p. 133): 'it is absolutely necessary to determine the territorial domains of each language and to protect autochtonous linguistic communities, whether or not they are threatened, in their traditional spreading areas. For the persistence of national languages cannot conceivably be guaranteed without ascribing to each an exclusive territory'

xiii When comparing the three oldest multilingual democracies, for example, it is often said that the secret of Switzerland's greater linguistic peace, relative to Belgium and Canada, resides in its much earlier implementation of the linguistic territoriality regime: there has never been a Germanization of Geneva analogous to the Frenchification of Brussels or the Anglicization of Montréal.

${ }^{\text {xiv }}$ Might equal dignity not be better expressed if the territories grabbed by each language were equal in terms of size, population or wealth? This would have absurd implications. If the shares are equal and small (say, close to the current share of the smallest linguistic community), this would leave the bulk of the planet up for linguistic grabs, reducing the operation of the linguistic territoriality regime to a marginal museum-like phenomenon. If the shares were equal and big (say, close to an equal share of the total surface, population or wealth of the world), this would require converting to a different native tongue the bulk of the population of the world. And anything in between would combine both drawbacks in varying proportions. Moreover, this sort of formula would involve an inbuilt perverse incentive to multiply the salience of linguistic differences so as to be able to grab a larger territory.

${ }^{\mathrm{xv}}$ On the linguistic situation in the Congo, see Mukash Kalel (2003). Obviously, assessing the likely sizes of the overall economic costs and benefits of such a four-language territoriality regime is bound to remain speculative. The role given to the Indian Union's sixteen national languages provides a sensible basis for such speculation, even though the populations involved are more massive (Telugu alone has more native speakers than there are Congolese citizens). Less obviously relevant but more comparable size-wise are the Finnish and Flemish cases: would Finland and Flanders be at the top of the OECD's PISA rankings of educational systems, had their schools not resolutely shifted from Swedish and French to Finnish and Dutch, respectively, in the XXth century? 


\footnotetext{
${ }^{x v i}$ A first formulation of the arguments in this and the next section can be found in Van Parijs (2000).

${ }^{\text {xvii }}$ See e.g. Stevens et al. (2006, p. 175): 'Korean adults, particularly those in the prime child-raising years, are much more likely to take their children along with them when visiting English-dominated countries than when visiting countries dominated by other languages'.

${ }^{\text {xviii }}$ As Arthur Schlesinger (1998, p. 127) sums it up in the case of the U.S.: 'We have shifted the basis of admission three times this century — from national origins in 1924 to family reunification in 1965 to needed skills in 1990'.

${ }^{\text {xix }}$ See e.g. Kapur and McHale (2003). To remittances stricto sensu one should add the accumulated assets repatriated at the time of their return by temporary migrant workers and migrants who decide to retire in their home country.

${ }^{\mathrm{xx}}$ See OECD (2002) for various country case studies.

${ }^{\mathrm{xxi}}$ In $L J 2.4$, I justify this free-riding as a form of compensation (more realistic than direct subsidies to language learning) for the free riding of English natives on the effort made by all others to produce a lingua franca.

${ }^{\text {xxii }}$ On the gradual and very unequal spread of English as the medium of higher education beyond the ground floor, see Ammon (2001) and Maiworm and Wächter (2002).
} 